\title{
Experimental study on cross wedge rolling process of aluminum alloy
}

\section{material}

\author{
Wen-shengYuan ${ }^{1, a}$, Lei-Wang ${ }^{1, b}$, Ting-xiang Yuan ${ }^{2, c}$ \\ ${ }^{1}$.School of Mechanical and Electronic Engineering, Shandong Jianzhu University, \\ Jinan, Shandong, 250101 \\ 2.Jinan Rapid CNC Machinary Engineering Co.,LTD \\ ajnrapid@163.com bwanglei@leopardspring.com ${ }^{\mathrm{c}} 46217897 @ q q . c o m$
}

Keywords: aluminum alloy cross wedge rolling shaft parts experiment

Abstract: in this paper, the passenger car of the axis parts (materials - aluminum alloy 6061) for cross wedge rolling technology analysis, design calculation of the cross wedge rolling die. The process of cross wedge rolling was simulated by computer technology, and the parameters were optimized. Friction condition, rolling temperature, mold temperature and rolling speed on the research and analysis; on the rolling process of workpiece forming rate, stress and strain distribution, the temperature distribution of the check. And in the DA46 type cross wedge rolling mill were a series of rolling experiments, verify the cross wedge rolling technology in rolling aluminum alloy materials of various process parameters, and get the qualified axis of aluminum alloy workpiece.

\section{Introduction}

Aluminum alloy material has many excellent properties, such as high strength, corrosion resistance, and so on, and now more and more people's attention. With the auto industry is becoming more and more lightweight, the passenger car parts market demand for aluminum alloy forging is more and more, such as the engine of the piston, connecting rod, rocker, etc.. Because of the characteristics of the aluminum alloy material, the properties of the alloy are very different from that of ordinary carbon steel, but the level of the aluminum alloy in China is far behind the developed countries.

For the complex shape of aluminum alloy forgings, due to not matched with the volume of distribution, production of a large quantity of forging flash, thus greatly increased the the production cost of the aluminum alloy forgings. At present, the production and development of complex aluminum alloy forging is very slow, and the production cost is very high, it is difficult to meet the increasing demand.

Cross wedge rolling technology as a kind of advanced metal plastic forming method, with its material utilizing rate is high, high production efficiency, long service life of the die, molding equipment tonnage small advantages, has attracted more and more people's attention, production of various carbon steel shaft has reached dozens. Due to carbon steel metal plasticity is good, high strength, cross wedge rolling technology has been relatively mature, mold design, manufacturing, and all of a set of effective methods and a lot of workpiece has realized the mass production.

In order to meet the requirements for the process of rolling aluminum alloy material, for aluminum alloy material of metal structure and plastic deformation characteristics of related research, in order to choose a suitable cross wedge rolling process parameters. 


\section{Aluminum alloy (6061) cross wedge rolling die design for automobile shaft}

Experimental Rolling: The rolled product pictures as shown in figure 1. This product is the central parts of typical automobile, material for 6061 aluminum alloy, demand. Traditional processing methods for turning. Therefore, the material utilization rate is low, the production efficiency is also very low. From Figure 2 we can see that the product is a non symmetry axis and the maximum section shrinkage rate is $70.2 \%$. Can be carried out a rolling, considering the shorter, the use of a mold piece of the process route two, as shown in figure 4.

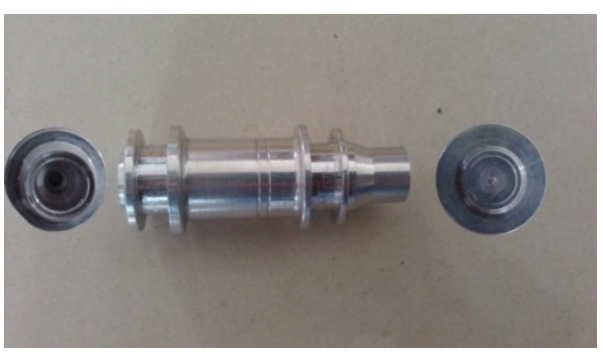

Fig.1 The workpiece

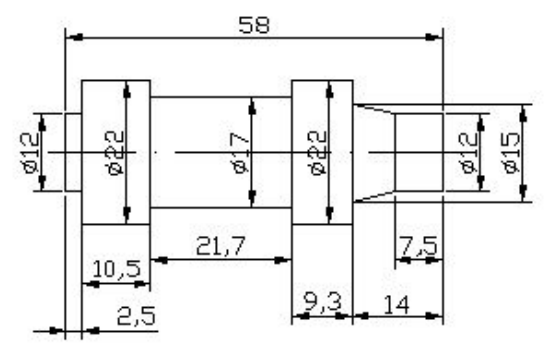

Fig.2 Two dimensional graph

Die design calculation. The design parameters used not only refer to the experience of carbon steel, but also the theoretical analysis of the aluminum alloy material. Such as Figure 3, 5 for the design of the two-dimensional mold expansion plan and its section.

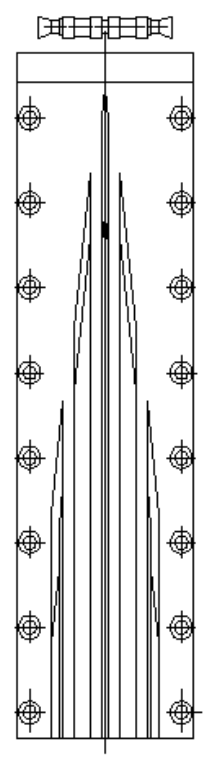

VIIITIIIs

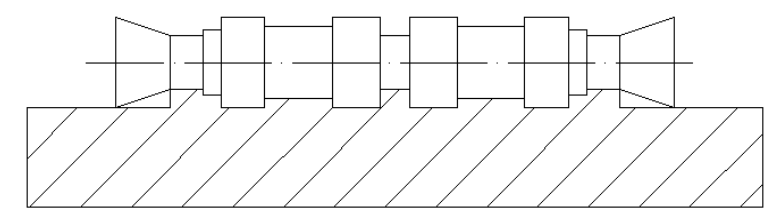

Fig.3 Die expansion drawing

Fig.4 Die section drawing

\section{Simulation analysis of cross wedge rolling process}

Establishment of geometric model of cross wedge rolling. Such as shown in Figure 5 for the tool of cross wedge rolling, rolling, a baffle plate of 3D assembly diagram, figure in the middle position of the aluminum alloy blank and die distribution installation in the mill roll from top to bottom, about aluminum alloy strip are arranged on the baffle. 


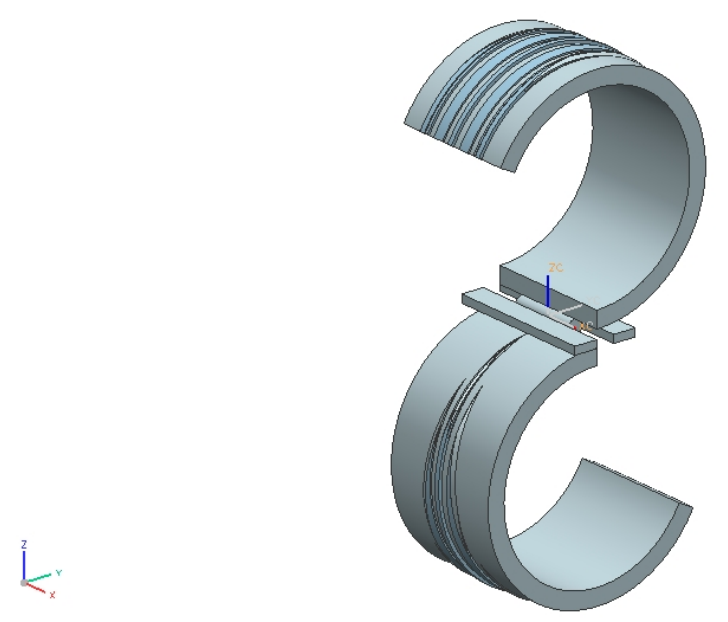

Fig.5 Three dimensional die drawing of cross wedge rolling

Set the initial conditions: set mold and workpiece in rolling process there is no relative sliding, movement of the mould in the whole rolling process for uniform rotation, initial speed of the die is equal to the rolling speed. The alloy elements of the 6061 aluminum alloy materials are $\mathrm{Si}]$ and $\mathrm{Mg}$, and the comprehensive performance is excellent. It is a typical deformation heat treatment of aluminum alloy. The rolling temperature is 350 .

Simulation result analysis. In order to meet the workpiece in the forming process of rotation, in order to more realistic simulated rolling environment, software through Boolean operations will cross wedge rolling die is divided into five parts, which are respectively the first wedge angle part, a first finishing part, the second wedge angle part, a second fine whole part and the base circle portion. Simulation results are shown in fig..

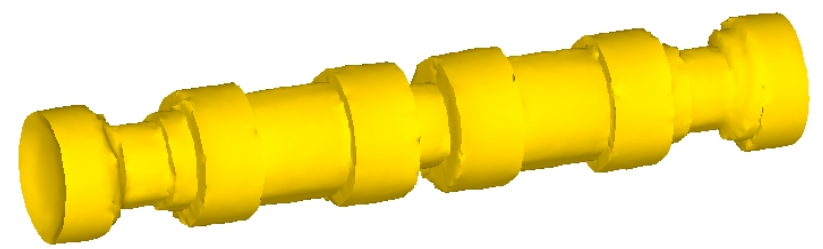

Fig.6 Rolling results

Analysis: in the whole process of the simulation of rolling, rolling forming are relatively stable, until the workpiece into mold fine phase there is no big problem. In addition to the surface quality of the workpiece is not ideal, have formed 6061 aluminum alloy rolling shaft.

Rolling force.Shown in Figure 7 for the simulation of rolling tries to, from the figure can be seen, maximum rolling force simulation about 700n, according to the past experience of rolling and rolling force is much less than rolling steel parts of the rolling force, which verify the aluminum alloy plastic forming is better than that of carbon steel.

Rolling stress, strain .Figure 8 and Figure 9 for the workpiece should stress and strain diagram, from can be seen, the rolling process of the maximum stress for $48.7 \mathrm{MPa}$, minimum stress for $0.155 \mathrm{MPa}$, the maximum strain was 28.5 and minimum strain was 0.444 , this section of the stress 


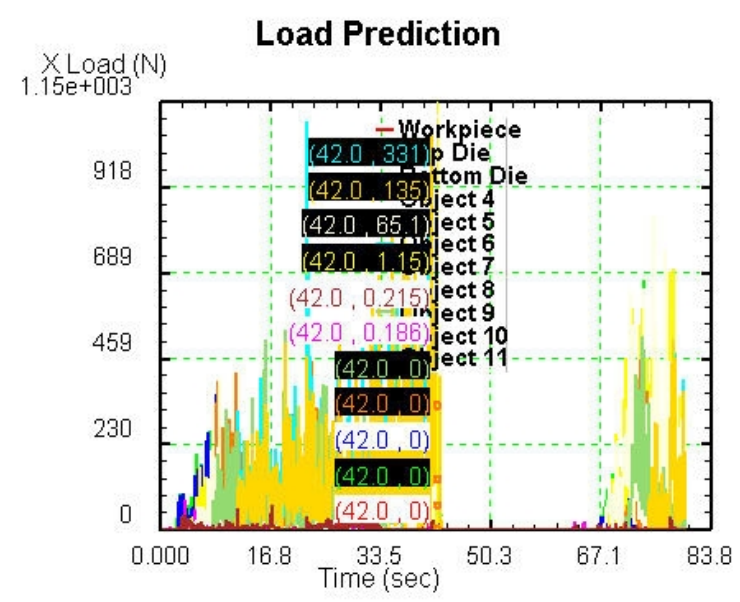

Fig.7 Rolling force

is 33mpa, strain was 24.6. The numerical and carbon steel compared is relatively small, is in line with the actual situation. Stress and strain decrease also cause the decrease of rolled piece heart tissue destruction probability, to ensure that the microstructure and properties of rolled piece heart.

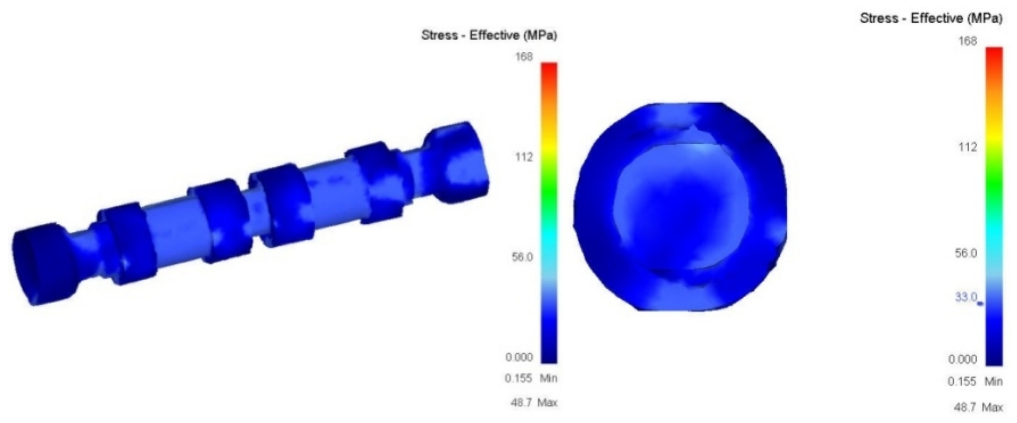

Fig.8 Stress

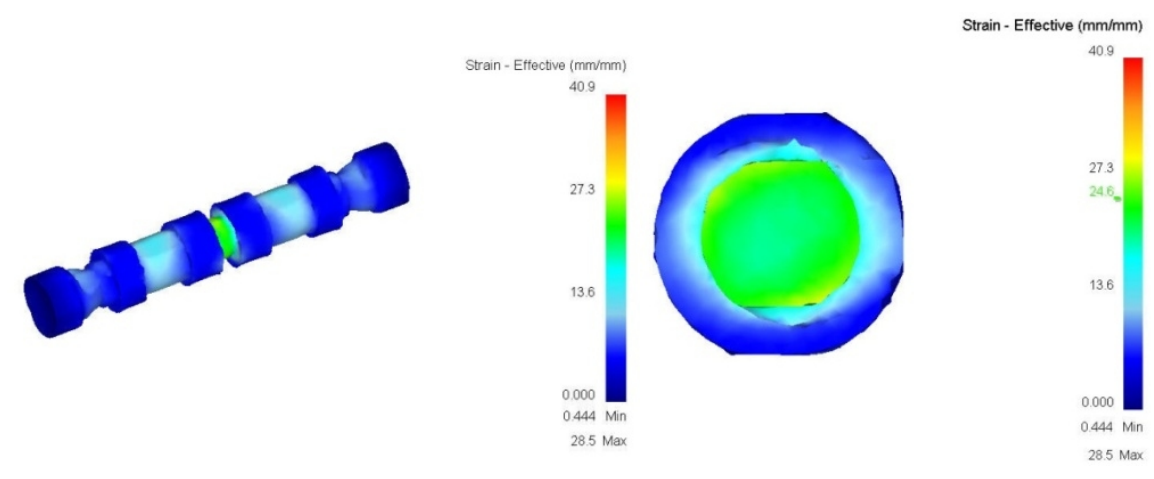

Fig.9 Strain

\section{Effect of temperature and rolling process of rolling forming process of cross wedge rolling}

The forging temperature of the 6061 aluminum alloy is generally 432-480, and the forging temperature range is narrow. Since the cross wedge rolling is different from the traditional forging, in order to be able to determine the more excellent rolling temperature. In this paper, a wider temperature range of 250--480 was used to study the performance of 6061. Under the same condition of friction, the rolling temperature is simulated, and the rolling force is 250,450 and 11 respectively. 


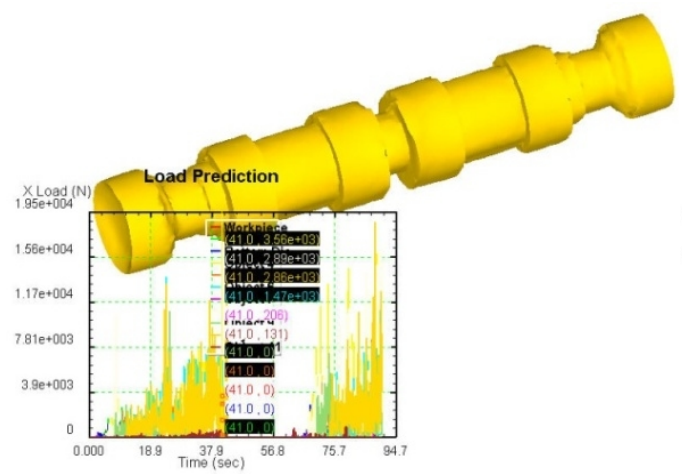

Fig.10 $250^{\circ} \mathrm{CRolling}$ force

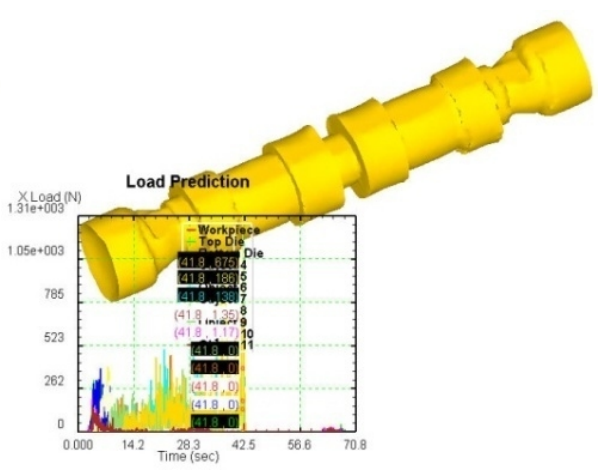

Fig. $11450^{\circ} \mathrm{C}$ Rolling force

As can be seen from the top of the figure, the maximum rolling force required at 250 is about $12500 \mathrm{~N}$, and the maximum rolling force required at 450 is about $523 \mathrm{~N}$. Through three times of simulation, can see very clear, under the three temperature conditions workpiece can eventually forming, higher rolling temperature, rolling force is small and through the surface of the workpiece compared 250 DEG $\mathrm{C}$ under the condition of forming the workpiece surface quality best; $350 \mathrm{DEG}$ $\mathrm{C}$ and 450 DEG $\mathrm{C}$ under the condition of rolling the last step not fully formed that higher rolling temperature, mold fine whole segment to the corresponding extension.

Effect of mold temperature on the rolling process in the process of cross wedge rolling Aluminum alloy plastic although better but the adhesion of larger, in the cross wedge rolling process, the mold or block plate and strip can also cause adhesion, which not only seriously affects the the surface quality of the workpiece, but also seriously affected the normal operation of the process of cross wedge rolling. Therefore in rolling and we have to mould and a guide plate is heated, the following is mold and a baffle plate temperature of $15 \mathrm{C}$ and $100 \mathrm{DEG} \mathrm{C}$, respectively of rolling stress and strain diagram. Under 15, the maximum rolling force is about $1300 \mathrm{~N}$, the maximum rolling force is about $1660 \mathrm{~N}$ at 100 , and the maximum rolling force is described in the previous 200 , which is about $689 \mathrm{~N}$.

As can be seen from the figure, mold temperature under the condition of 15 DEG C workpiece's maximum stress for $67.6 \mathrm{MPa}$, minimum stress to $0.459 \mathrm{MPa}$, the maximum strain was 18.1 , the minimum strain was 0.416 ; condition of $100{ }^{\circ} \mathrm{C}$ under the workpiece's maximum stress $142 \mathrm{Mpa}$ and the minimum stress is $0.279 \mathrm{MPa}$, the maximum strain was 18.9 and minimum strain

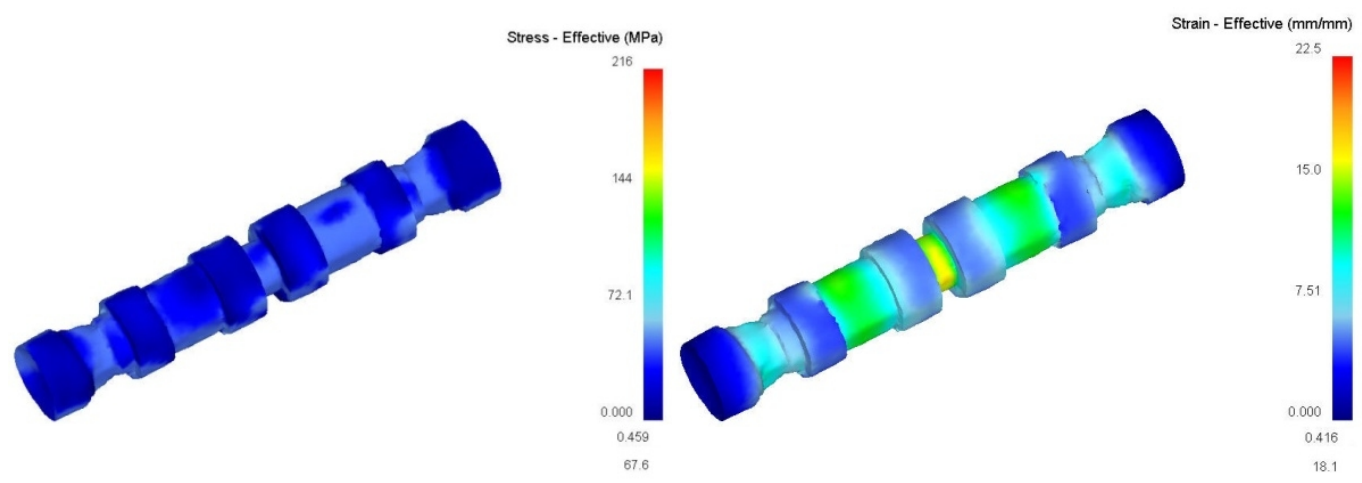

Fig.12 The stress at the die temperature of $15^{\circ} \mathrm{C} \quad$ Fig.13The Strain at the die temperature of $15^{\circ} \mathrm{C}$ 


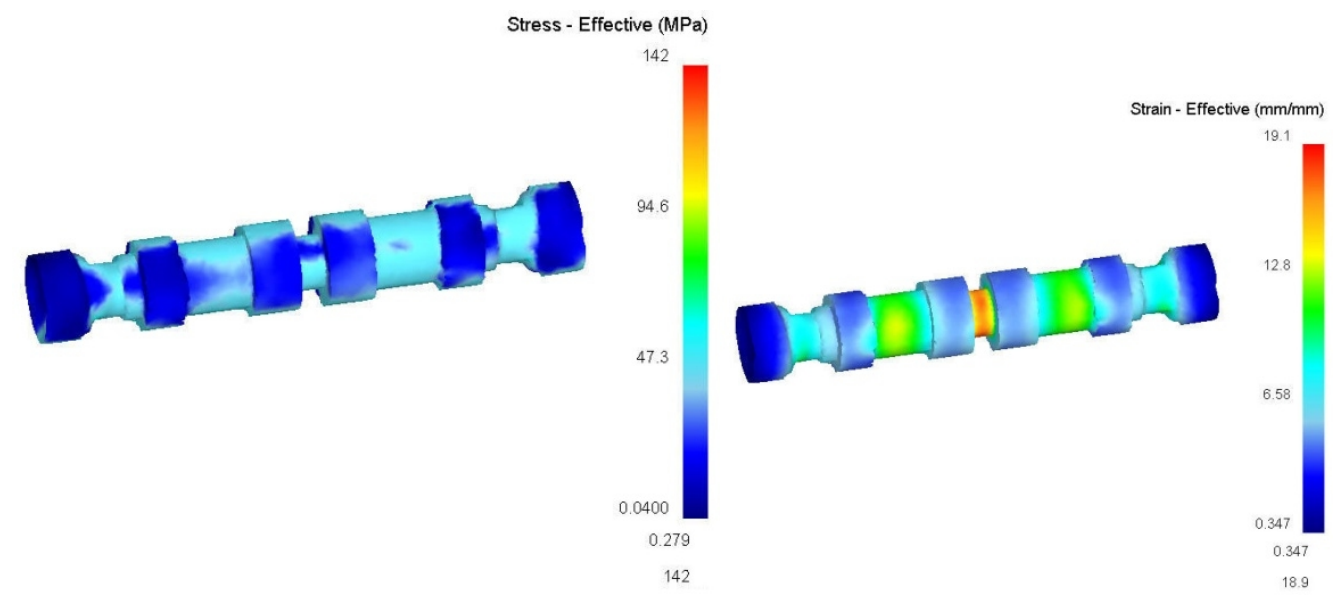

Fig.14The stress at the die temperature of $100^{\circ} \mathrm{C}$ Fig.15The Strain at the die temperature of $100^{\circ} \mathrm{C}$ was $0.347 ; 200{ }^{\circ} \mathrm{Cunder}$ the condition of rolling should be the stress and the strain of the front have been described, and the maximum stress for $48.7 \mathrm{MPa}$, minimum stress for $0.155 \mathrm{MPa}$, the maximum strain was 28.5 and minimum strain was 0.444 .

\section{1 aluminum alloy material wedge rolling experiment}

Wedge rolling equipment.The diameter of $25 \mathrm{~mm} 6061$ aluminum alloy rolling bars, the corresponding rolling experiments in DA46-400 type cross wedge rolling mill. DA46-400 type cross wedge rolling mill is an integral two roll cross wedge rolling mill.

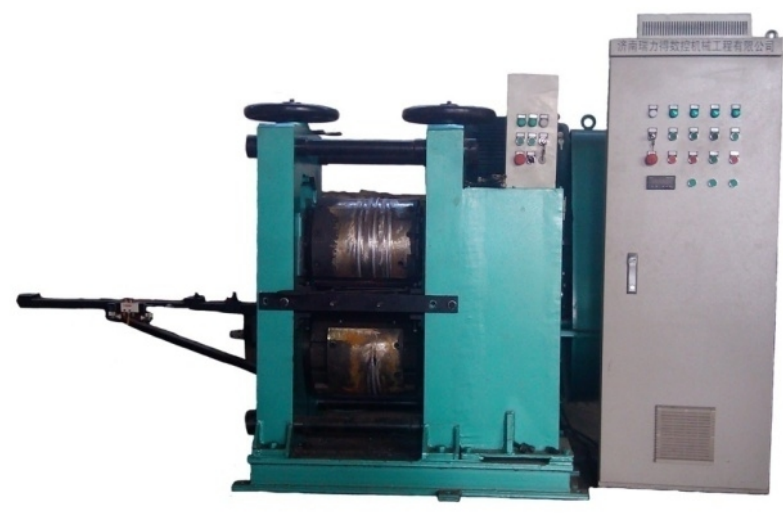

Fig.16DA46-400 type cross wedge rolling mill

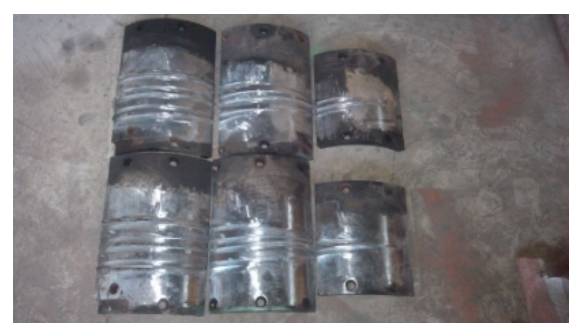

Fig.17 Experimental mold

Experimental mold.According to the design of our production axis such as cross wedge rolling test shown in Figure 17 with the mold.In order to ensure the surface quality of the workpiece, the surface of the die for polishing treatment. In order to ensure that the two pieces of the mold with close, to repair the end of the mold grinding, so as to ensure the quality of the mold with the surface

The heating of blank. The aluminum alloy bar is heated in a box type electric furnace, and the heating temperature is 35030 . In order to ensure the heating of the bar and the uniform, setting the holding time is $25 \mathrm{~min}$. Considering the start and stop of the controlled rolling mill, the high speed of the roller is not set, and the speed of the rolling process will be set to $4 \mathrm{r} / \mathrm{min}$.।

Experimental results.Rolling the appearance chart as shown in Figure 18, and workpiece surface smooth, scraper phenomenon rarely, each axis can form, the size and shape of the echoed drawings design requirements. . 


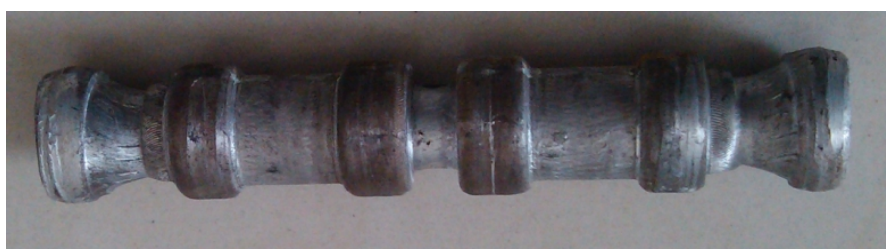

Fig.18 Rolling parts

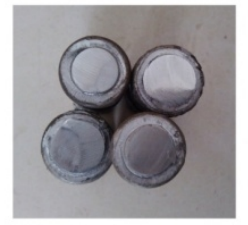

Fig.19 Cross section

The workpiece from the cross section cut, with a polishing machine polishing section of the workpiece, the cross section images as shown in figure 19. Uniform tissue in the heart of the workpiece, there is no voids and other defects, wedge cross rolling billet process can completely meet the requirements of the parts.

\section{Conclusion}

The process parameters of the cross wedge rolling process of aluminum alloy shaft parts, the general mould stretching angle $\beta=6^{\circ}$, the forming angle $\alpha=18^{\circ}$, the section shrinkage rate is less than $70 \%$;

Rolling rolling temperature and rolling speed to cooperate with each other, when under the condition of high temperature and rolling to rolling speed regulating higher; when the rolling temperature is low, the rolling speed regulation of the low. Cross wedge rolling forming of aluminum alloy, the heating temperature at $300-350{ }^{\circ} \mathrm{C}$, the heating temperature of mold in $150-200$ ${ }^{\circ} \mathrm{C}$

In order to normal rolling, rolling aluminum alloy parts, not on a molding surface adding agent. Although aluminum alloy material plasticity is good, but in the high temperature plastic deformation of demoulding is not easy, namely the workpiece surface and the mould surface prone to adhesion, which led to the decline in the quality of workpiece surface. But when applying graphite, rotating conditions are no longer satisfied when rolling, the rolling sliding occurs, will eventually be rolled flat. In order to make the workpiece surface quality to meet the requirements, timing of mould surface grinding.

Through theoretical analysis and experimental rolling, cross wedge rolling forming of 6061 aluminum alloy shaft parts is feasible. The final workpiece surface and internal quality are in line with the requirements of this forming production efficiency and finished product rate is high and stable product quality.

\section{Reference}

[1] Yuan Wensheng, Wang Zhonglei, Design system of cross wedge rolling die based on Delphi Forging equipment and manufacturing technology, 2005(6)

[2] Wang Zhonglei, Yuan Wensheng, Development of the demonstration system of cross wedge rolling process, Forging equipment and manufacturing technology, , 2006(4)

[3] Gong Xiaotao, Yang Fan,Development of isothermal forging technology of aluminium alloy Metal processing, 2010,

[4] Dong Xuanpu, Li Weihua, Research and application of the lubrication mechanism of aluminum alloy hot forging die, Forging technology, 2010

[5] PATER Zbigniew, GONTARZ Andrzej, TOFIL Arkadiusz. Analysis of the Cross-Wedge Rolling Process of Toothed Shafts Made from 2618 Aluminium Alloy[J]. Shanghai Jiaotong Univ. (Sci.), 2011, 
[6] Gong Guichun, Research on the forming law of the aluminum alloy hollow shaft parts based on DEFORM--3D, Jiangsu: Jiangsu University, 2010

[7] Zhao Peifeng., Study on cross rolling deformation of 6061 aluminum alloy, Beijing: Mechanical Science Research Institute, 2006

[8] Peng Yan, Lin Yanhong., Process design of isothermal forging of 6061 aluminum alloy forging, Southern metal. 2012.

[9] Zhang Naiwei, Wang Nan, Deformation characteristics of cross wedge rolling forming of stepped shaft, Journal of Hebei University of Engineering 2010, 